\title{
Development and clinical feasibility testing of the Pain Treatment Planning Questionnaire
}

Susan M Tupper, JoAnn Nilson, Jennifer King, Pamela Downe, Nancy Hodgson, Tara Schlosser, Kelsey Brose

Background: Chronic pain is common in people with bleeding disorders and can complicate clinical management, impair quality of life, and contribute to disability. People living with bleeding disorders often seek advice on pain management from the bleeding disorder treatment team; however, lack of condition-specific assessment tools to guide clinical communication about pain are a barrier to care.

Aims: To develop and examine the clinical feasibility

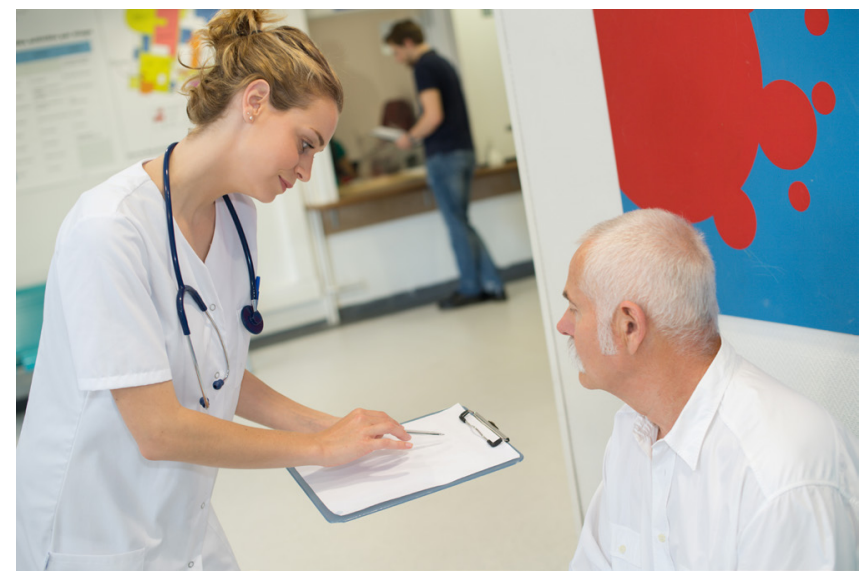

The development of a patient-reported outcome tool for pain, specific to people with bleeding disorders, could help facilitate the pain assessment and discussion of treatment options in bleeding disorder clinics.

of a patient-reported outcome (PRO) tool designed to facilitate pain assessment and support clinical communication about pain for adults attending outpatient bleeding disorder clinics. Methods: Tool development involved patient cognitive interviews and item refinement by a multidisciplinary clinician and patient working group. Clinical feasibility of the tool was evaluated with a survey of a small clinical sample in an outpatient bleeding disorder clinic. The Pain Treatment Planning Questionnaire (PTPQ) contains 28 items on the pain experience and treatments used to manage or prevent pain. Results: Participants completing the feasibility testing ( $n=42,62 \%$ male) reported mild mean pain scores (usual pain $\mu=2.4$, $\mathrm{SD}=2.0$ ) with the majority (57.1\%) reporting persistent

This is an Open Access article distributed under the terms of the Creative Commons Attribution-NonCommercial-NoDerivs License (https://creativecommons.org/licenses/by-nc-nd/3.0/) which permits use and distribution in any medium, provided the original work is properly cited, the use is non-commercial, and no modifications or adaptations are made. Copyright is retained by the authors. 
pain in the past 30 days. Median PTPQ completion time was five to seven minutes and mean item response rate was $95.2 \%$. The majority (95.2\%) of participants found the questionnaire easy to understand, reported no difficulty understanding items, and recommended no changes to the questionnaire. Conclusions: Preliminary testing among a small sample in a clinical setting suggests that the PTPQ is a clinically feasible, acceptable, condition-specific PRO pain assessment tool for adult patients with bleeding disorders. Further testing is required to determine if the PTPQ affects treatment decision-making and patient outcomes.

Keywords: Pain assessment, chronic pain, bleeding disorders, patient-provider communication, tool development

ain is common among people with bleeding disorders. Approximately $57 \%$ of adults with haemophilia over age 18 years report daily joint pain ${ }^{[1]}$, and joint pain is also common among adults with moderate or severe von Willebrand Diseases (VWD), both for those who report joint bleeds $(44 \%)$ and those who do not $(18 \%)^{[2]}$. Pain often interferes with daily activities for those with bleeding disorders and has negative associations with quality of life and mental health ${ }^{[3]}$. Thirty-nine per cent of adults with haemophilia report that their pain is not well managed, and over half report that they rely on the bleeding disorder care team for pain management advice ${ }^{[4,5]}$. Guidelines call for increased attention to pain assessment and management in comprehensive care of people with bleeding disorders and highlight the need for condition-specific patient reported outcome (PRO) measures ${ }^{[5-10]}$. To meet that call for action, multidisciplinary bleeding disorder clinicians will need the knowledge, skills, and tools to effectively assess and communicate with patients about pain in order to develop acceptable and impactful treatment plans. Chronic pain is a complex, biopsychosocial experience requiring a comprehensive focused assessment that covers multiple domains, including sensory, affective, and motivational aspects of pain, impact of pain on psychological and physical functioning, and preferred treatment approaches ${ }^{[11-13]}$. No pain assessment tools specific to bleeding disorders were found in the literature that included all of these domains.

Management of pain may require pharmacologic and non-pharmacologic treatment interventions as well as education and skills training for self-management ${ }^{[14-15]}$. Communication between healthcare providers and patients is a critical first step in developing an assessment-based care plan that meets individuals' needs ${ }^{[16-19]}$. Healthcare providers play a critical role in enhancing patients' ability to adhere to treatment plans by providing recommendations, education to build knowledge, and skills training to build self-efficacy for pain and disease self-management ${ }^{[18,20]}$. Without explicit efforts to comprehensively assess and discuss pain management options, people living with frequent pain may neglect to raise issues about pain with their bleeding disorder clinicians, thinking that nothing can be done to change long-standing pain, and the care team may fail to fully understand the patient's pain management needs or constraints on their ability to follow through on recommendations ${ }^{[211}$. Therefore, communication with patients about their treatment goals, values, and available treatment alternatives may improve treatment planning, foster self-management, and result in better patient outcomes ${ }^{[181}$. PRO tools facilitate and expedite this communication, particularly when multiple heath care providers are involved in care provision ${ }^{[17]}$.

We describe the development and clinical feasibility of a condition-specific PRO tool, based on a small clinical sample, that can be used in outpatient bleeding disorder clinics to facilitate pain assessment and communication about treatment options. The Pain Treatment Planning Questionnaire (PTPQ) was codesigned with patient and multidisciplinary clinician input through an iterative process involving working group meetings, patient cognitive interviews, and examination of feasibility in a clinical setting.

\section{METHODS}

A three-step process was used for development of the PTPQ ${ }^{[22]}$ :

1. Conceptual framework and item selection - Identify important measurement domains for the tool based on expert consensus and literature review

2. Item and instrument refinement - Identify and pilot test relevant domain items and measurement properties through patient cognitive interviews

3. Clinical feasibility evaluation - Evaluate length of time to complete, ease of understanding of the questionnaire, and participant perceptions of acceptability.

Step 1: Conceptual framework and item selection The original idea for the PTPQ arose from a team planning meeting for a province-wide bleeding 
disorders program in Saskatchewan, Canada in April 2014. The meeting was attended by 27 people including four patient/family representatives, multidisciplinary bleeding disorder clinicians (four haematologist physicians, four nurses, five lab technicians, three physical therapists, and two social workers), two program managers/decision-makers, two administrative staff, and a strategy consultant on pain quality improvement. Clinicians and patient/ family representatives identified pain as an important component of living with a bleeding disorder that could be more adequately addressed through improved clinical communication. A small working group was convened to develop a tool that would address this need. The working group included one patient representative, the pain strategy consultant, and seven multidisciplinary clinicians from the provincial bleeding disorders program: two haematologist physicians, three nurses, a physical therapist, and a social worker.

One team member (ST) searched for published literature on Ovid MEDLINE to identify key references for pain assessment domains and pain treatment practice guidelines for bleeding disorder populations. All search terms were expanded and included (haemophilia OR von Willebrand disease) AND pain, AND (guideline OR assess* OR evaluati*OR too ${ }^{\star} O R$ instrument*OR best practice*OR recommendation*OR standard*). English language, published, peer-reviewed journal articles identified in the search were reviewed. Extracted data included pain assessment tool names, domains, and item wording or scale properties (e.g. Numeric Rating Scale, pain intensity, 0 to 10 scale, 0 is "no pain" and 10 is "most pain possible"), and a list of common medication and non-drug pain treatments (e.g. opioids, acetaminophen/paracetamol, ankle brace, cognitive behavioural therapy). Extracted data were presented to the working group for discussion and items were selected for a prototype of the $P T P Q$, which was created through discussion and group consensus.

\section{Step 2: Item and instrument refinement}

Research ethics approval was obtained from the University of Saskatchewan Behavioral Research Ethics Review Board (BEH 15-71). Cognitive interviews ${ }^{[23,24]}$ were conducted with a purposive sample of adults with bleeding disorders between March and September 2015. The sample included participants with either haemophilia A, haemophilia B, or VWD who were known by clinician members of the research team $(\mathrm{JK}, \mathrm{JN}$, $\mathrm{NH}$ ) to have diverse pain experiences related to their bleeding disorder. After obtaining informed consent, participants completed the PTPQ in a "think-aloud" format ${ }^{23,24]}$. A single interviewer (ST) asked participants a set of predetermined questions with additional probing questions based on their responses during the completion of the questionnaire (see Appendix A for interview guide). This elicited a greater understanding of their interpretation of the PTPQ items and the responses provided, and suggested item revisions ${ }^{[25]}$. Interviews were audio-recorded. Two team members $(\mathrm{ST}, \mathrm{JK}$ ) reviewed sets of two recordings at a time, first independently, and a second time together to discuss if revisions to the PTPQ were warranted. Two team members (PD and $\mathrm{JK}$ ) reviewed the revised $P T P Q$ version and recordings and approved changes prior to use in the next successive pair of interviews. Interview recruitment ceased when two consecutive interviews resulted in no further substantive changes to the prototype. A clinical psychologist and pharmacist were consulted to provide feedback on the prototype since these disciplines were not represented on the questionnaire development working group. A second working group meeting was held to review and finalise the PTPQ prototype prior to use in the clinical feasibility trial. This process was used to ensure face and content validity of the questionnaire from both the patient and the clinician perspectives. After completion of the clinical feasibility evaluation, a final working group meeting was held to discuss clinical use of the PTPQ and to determine if any final changes were recommended.

\section{Step 3: Clinical feasibility evaluation}

A convenience sample of 42 patients was recruited by a non-clinician researcher (ST) from patients attending the bleeding disorder clinic between October 2015 and February 2017. Participants were adults (17 years of age and older) with a diagnosis of either haemophilia A or haemophilia B (any severity) or VWD (any type), able to read grade 8 level of English or higher, without physical or cognitive impairments that would prevent selfreport. Upon obtaining informed consent, participants completed the following questionnaires:

1. $P T P Q$

2. Demographic questionnaire, including questions on age, sex, bleeding disorder diagnosis and severity

3. Chronic Pain Grade Scale (CPGS), a valid and reliable seven-item questionnaire used to categorise severity of chronic pain into five hierarchical grades according to pain intensity and pain-related disability ranging from grade 
0 (no pain problem) to grade 4 (high disability that is severely limiting) ${ }^{[26.27]}$. The CPGS is recommended for use with adults with any musculoskeletal chronic pain condition ${ }^{[28]}$ and has demonstrated good scale reliability (Cronbach's alpha $=0.91$ and average item-total correlation $=0.76$ ) $^{[26]}$. Two-week test-retest reliability of the Italian version was $k=0.81^{[29]}$. Convergent validity was confirmed with highly significant associations (all $p<0.001$ ) between CPGS categories and SF-36 general health status questionnaire scores for physical, psychological, social, general health, and bodily pain.

4. Clinical feasibility questionnaire, including question on patient perception of difficulty/ease of understanding the PTPQ questions (five-point Likert scale), approximate time to complete the PTPQ (five categories, from "less than two minutes" to "more than ten minutes"), and five yes/no questions with an open text option for further comment on patient perceptions about feeling informed about their pain management plan, feeling that adequate information about pain was received during the clinic visit, whether any of the questions on the PTPQ were not important, whether any of the questions on the PTPQ were confusing, or whether they recommended any other changes to the questionnaire.

Associations between CPGS categories and PTPQ outcomes were tested. It was expected that participants from higher disability categories would report higher composite pain scores (average of four pain intensity questions) and would be more likely to report pain interference with activities and mood.

\section{RESULTS}

Step 1: Conceptual framework and item selection Narrative data were extracted from 11 articles found in the literature review that described pain assessment tools or domains and recommended pain treatments. Consensus on items to include in the PTPQ prototype was achieved with a single working group meeting. These items were collated into a two-page PTPQ prototype that was used in cognitive interviews. Consultation with the psychologist and pharmacist resulted in minor revisions, including the addition of common medication brand names to improve patient recognition.

\section{Step 2: Item and instrument refinement} Nine adults, ranging in age from 19 to 71 years (56\% male), completed cognitive interviews. Participants had haemophilia $A$ ( $n=4 ; 1$ mild, 3 severe), haemophilia $B$ $(n=1$, severe), and VWD $(n=4)$. Interviews ranged in length from 30 to 90 minutes. Participants provided feedback on organisation of the questionnaire, item wording, and redundancy. For example, the initial prototype had a one-week recall period for pain severity questions, which was increased to a one-month recall to capture the pain experiences of individuals who experience pain less frequently. Further revisions to the PTPQ prototype wording were made subsequent to the working group meeting following the clinical feasibility study. These revisions included the addition of four items regarding perception of self-efficacy for self-management with different treatment categories, rated on an ordinal scale from 0 to 10, with higher numbers representing perception of better management. Since the items on perception of self-management were added after the clinical feasibility study, no data are available on these items (see Figure 1 for PTPQ development process).

Figure 1: Iterative PTPQ development process

Planning meeting with patients, clinicians, manager, and pain consultant

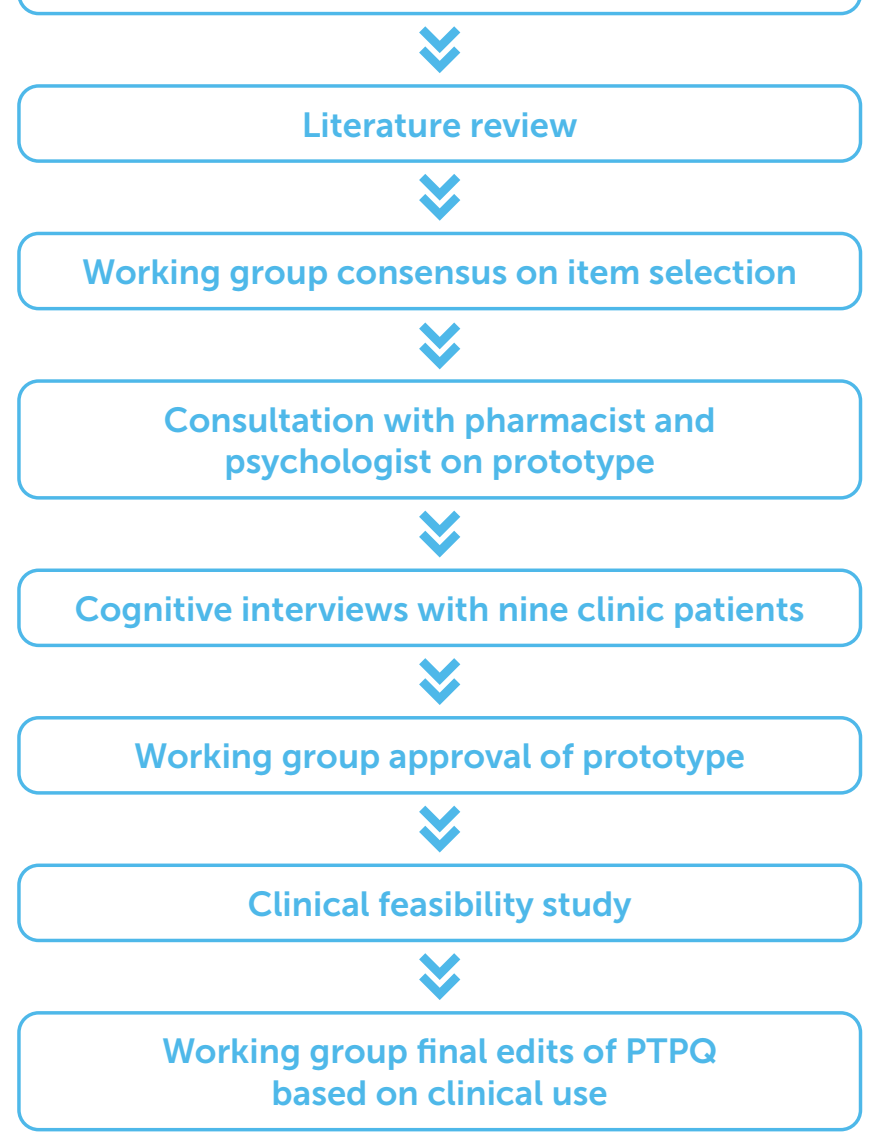


Table 1: Clinical feasibility study participant characteristics $(n=42)$

\begin{tabular}{l|l}
\hline CHARACTERISTIC & N (\%) \\
Male & $26(61.9)$ \\
\hline Female & $16(38.1)$ \\
\hline Diagnosis & $18(42.9)$ \\
\hline VWD & $17(40.5)$ \\
\hline Haemophilia A & $7(16.7)$ \\
\hline Haemophilia B & \\
\hline Chronic Pain Grade Scale & $1(2.4)$ \\
\hline Grade 0 = Pain Free & $27(64.3)$ \\
\hline Grade 1 = Low disability, low intensity & $7(16.7)$ \\
\hline Grade 2 = Low disability, high intensity & $3(7.1)$ \\
\hline $\begin{array}{l}\text { Grade 3 = High disability, } \\
\text { moderately limiting }\end{array}$ & $4(9.5)$ \\
\hline $\begin{array}{l}\text { Grade 4 = High disability, } \\
\text { severely limiting }\end{array}$ &
\end{tabular}

Step 3: Clinical feasibility evaluation

A convenience sample of 42 adults (age range 17 to 82 years; $\mu=46.7$ years, $S D=18.3$, Shapiro-Wilk Test for normal distribution $\mathrm{p}=0.066$ ) participated in the clinical feasibility study (see Table 1 for participant characteristics). All participants meeting study inclusion criteria were invited to participate during a clinic visit by a researcher who was not a member of the multidisciplinary care team (ST). A total of 46 patients were approached; four chose to not participate due to lack of interest (91\% recruitment rate). Participants had a median completion time of five to seven minutes and mean item response rate of 95.2\% for the PTPQ. Questions most likely to be left blank were open text fields such as, "How often and what activities did you limit?" (50\% not completed) and, "Treatment goals: how can we help you?" (35.7\% not completed). The majority of participants ( $n=40$; $95.2 \%)$ reported no difficulty understanding items. In response to the question, "Were any of the questions not important?" one participant identified the questions on emotional impact and one participant identified the prevention and physical treatments questions. In response to the question, "Were any of the questions confusing?" one patient responded, "I don't have a lot of pain with my bleeding disorder so I don't feel as I could fully answer the questions on pain as I don't have any." In response to the statement, "Please describe any changes you recommend to improve the questionnaire (e.g. change wording, add questions, remove questions)," the majority of participants either left the question blank or responded with positive feedback, such as "It is clear and easy to fill out," or "Great info and questions." One participant suggested increasing the amount of space to allow more room to explain responses to questions.

\section{Pain characteristics reported on the PTPQ}

The majority (73.8 \%) of participants reported pain at the time of the study (non-zero score for the "current pain" question), with a mean score of 2.3 (range $0=$ "No pain" to 10 = "Most pain possible") to the question, "How would you rate your pain right now?" The majority of participants (57.1\%) reported persistent pain in the past month, defined as a non-zero score to the question, "How would you rate the lowest level lowest of pain you have had this past 30 days?" (see Table 2 for pain characteristics identified on the PTPQ). The body locations of pain most frequently selected on the diagram in response to the question "Indicate on the diagram below where you felt bodily pain from any cause in the past 30 days," were the forearm, wrist, or hands (36\% of total sample), and the lower back, shoulders, ankles or feet (31\% of total sample for each area; see Figure 2 for locations selected). The majority of participants (71.4\%) identified two or more locations of pain on the body diagram. The most common descriptive words selected were "aching" (67\% of total sample) and "sharp" (38\%). Almost half (47.6\%) of participants selected at least one word typically used to describe neuropathic pain and paraesthesia symptoms, e.g. burning, electric shocks, tingling, prickling, bursting, shooting. Almost half of the participants did not report pain interference with activities or mood (47.6\%), 33.3\% reported interference with both, and $14.3 \%$ reported interference with either activities or mood (4.8\% missing).

The most common open-text response to the question "What made your pain less noticeable in the past 30 days?" were activities ( $n=19 ; 45.2 \%$ of all participants) such as "keeping active" or "exercises". In response to the question, "What made your pain worse in the past 30 days?" participants provided equal frequencies of responses ( $n=17 ; 40.5 \%$ ) for activity or work (e.g. "too much activity") and prolonged positioning (e.g. "prolonged sitting"). Over half of all participants reported a typical daily pattern to pain intensity, with the majority reporting worst pain in the evening ( $n=9 ; 21.4 \%)$ or morning ( $n=7 ; 16.7 \%)$.

Due to low numbers in CPGS categories, a dichotomous variable was created for no pain/low disability (CPGS categories 0-2) and high disability (CPGS categories 3 and 4). Composite pain scores in both groups were normally distributed and had equality of variance. Mean composite pain scores 
were significantly different between dichotomous CPGS groups on Independent Samples T-test $(\mu$ pain=2.6 [1.6] no pain/low disability; $\mu$ pain $=4.4$ [2.2] high disability; $\mathrm{p}=0.013, \mathrm{Cl}=0.41,3.26$ ). Trends towards group differences in proportions of participants reporting mood and activity interference between no pain/low disability and high disability groups were identified (Table 3). Although the statistical tests are reported, these results can only be interpreted as trends and should be interpreted with caution due to the unacceptably low numbers in individual cells.

Figure 2: Body locations of pain identified on PTPQ (\% of total sample)

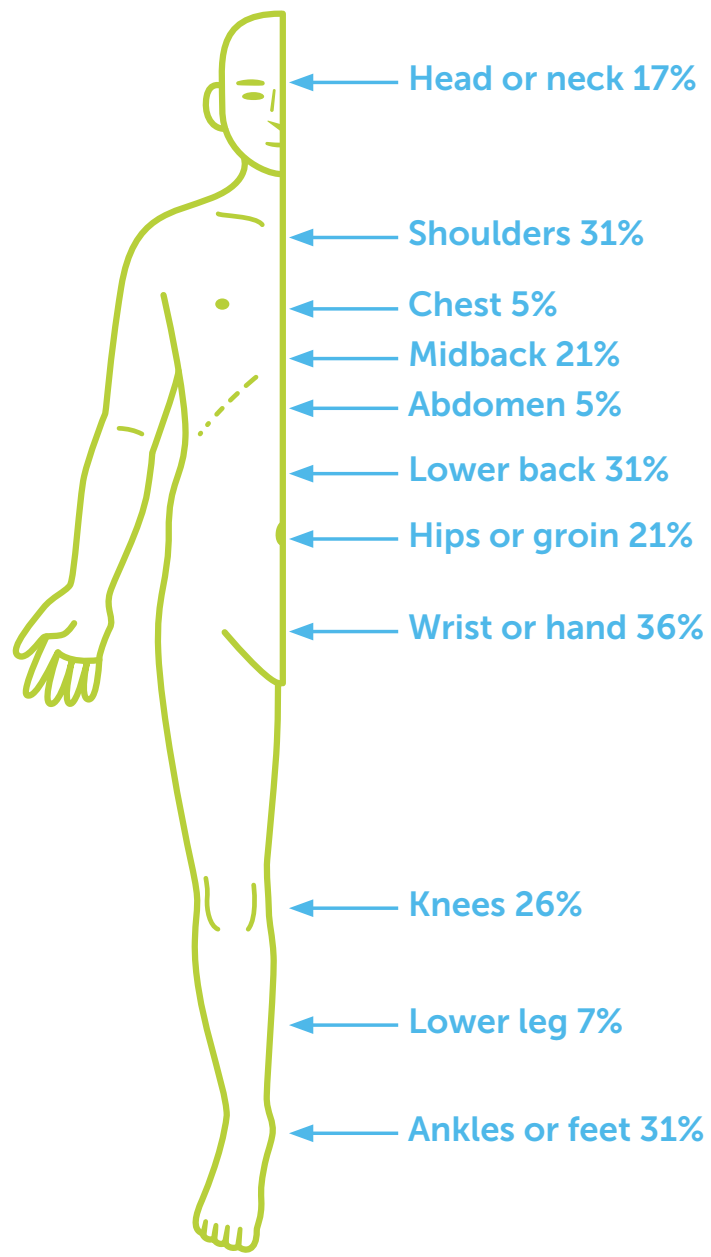

\section{DISCUSSION}

The PTPQ is a 28-item condition-specific PRO instrument developed for use in the outpatient setting to guide communication about pain and pain treatment between patients with bleeding disorders and multidisciplinary healthcare providers (see Appendix B). It is a multidimensional tool that measures a number of constructs, including body locations of pain, pain severity, pain frequency, descriptive qualities, pain interference, palliating and provoking factors, timing, satisfaction with treatment,

Table 2: Pain characteristics identified on PTPQ (sample $n=42$ unless otherwise specified)

\begin{tabular}{l|l} 
& $\begin{array}{l}\text { SAMPLE } \\
\text { MEANS } \\
\text { (SD) OR }\end{array}$ \\
\hline PROPORTIONS \\
\hline CHARACTERISTIC & $2.3(2.0)$ \\
\hline Lowrent pain (0-10) & $1.5(1.8)$ \\
\hline Worst pain in past 30 days (0-10) & $5.3(2.8)$ \\
\hline Usual pain in past 30 days (0-10) & $2.4(2.0)$ \\
\hline Number of pain descriptive words & $3.9(3.1)$ \\
\hline $\begin{array}{l}\text { Pain typically worse during certain } \\
\text { time of day (\% "yes") n=41 }\end{array}$ & $53.7 \%$ \\
\hline $\begin{array}{l}\text { Pain interference with activities } \\
\text { (\% "yes") n=40 }\end{array}$ & $37.5 \%$ \\
\hline Pain interference with mood (\% "yes") & $47.6 \%$ \\
\hline $\begin{array}{l}\text { Use pharmaceutical treatments } \\
\text { (\% selecting at least one treatment) }\end{array}$ & $85.7 \%$ \\
\hline $\begin{array}{l}\text { Use psychological treatments } \\
\text { (\% selecting at least one treatment) }\end{array}$ & $47.6 \%$ \\
\hline $\begin{array}{l}\text { Use preventative treatments } \\
\text { (\% selecting at least one treatment) }\end{array}$ & $69.0 \%$ \\
\hline $\begin{array}{l}\text { Use physical treatments (\% selecting } \\
\text { at least one treatment) }\end{array}$ & $69.0 \%$ \\
\hline $\begin{array}{l}\text { Achieve recommended weekly } \\
\text { exercise levels (\% of total reporting } \\
\text { cardiovascular exercise) }\end{array}$ & $19.0 \%$ \\
\hline
\end{tabular}

Table 3: Participants reporting activity limitations or mood interference within CPGS clusters

\begin{tabular}{|c|c|c|c|c|}
\hline & & \multicolumn{2}{|c|}{ CPGS CATEGORY } & \multirow[b]{2}{*}{ SIG. * } \\
\hline & & $\begin{array}{l}\text { NO PAIN/LOW } \\
\text { DISABILITY (CPGS 0-2) }\end{array}$ & $\begin{array}{l}\text { HIGH DISABILITY } \\
\text { (CPGS 3-4) }\end{array}$ & \\
\hline \multirow{2}{*}{ Activity limitations from pain } & No & 23 & 2 & \multirow{2}{*}{$p=0.081$} \\
\hline & Yes & 10 & 5 & \\
\hline \multirow{2}{*}{ Mood interference from pain } & No & 21 & 1 & \multirow{2}{*}{$p=0.041$} \\
\hline & Yes & 14 & 6 & \\
\hline
\end{tabular}

\footnotetext{
* Fisher's Exact Test used due to small sample size
} 
a checklist of treatments, exercise participation, and self-efficacy to manage pain with different categories of treatment. Similar to any focused pain history, these different constructs can be used to guide further investigations into the underlying mechanisms of pain (i.e. nociceptive vs. neuropathic), to better understand the impact of pain on the individual, and guide pain treatment planning. Given the high prevalence and impact of pain in this population described in previous studies ${ }^{[2-4,9,30,31]}$ and the current sample, as well as patient reports of dissatisfaction with pain management described in previous research ${ }^{[4]}$, discussion about pain at regular clinic visits should be considered a critical component of person-centred care. Use of a tool, such as the PTPQ, to facilitate discussion about pain may improve clinicians' understanding of patient pain experiences and patient understanding of appropriate treatment and selfmanagement options ${ }^{[18,19]}$.

A general population survey conducted in Germany by Hauser et al. (2015) found that $71.5 \%$ of those surveyed did not have chronic pain, compared to only $2.4 \%$ of the current clinical sample who reported no chronic pain ${ }^{132]}$. The survey reported that $19.1 \%$ had non-disabling chronic pain (CPGS scores 1 or 2), and $7.3 \%$ had disabling chronic pain (CPGS scores 3 or 4 ), compared to the current study in which $81.0 \%$ had non-disabling chronic pain, and $16.6 \%$ had disabling chronic pain. Higher prevalence of chronic pain that interferes with physical function among those with haemophilia has been previously reported. In a survey of participants with haemophilia A or B in which $57 \%$ reported daily pain, Elander et al. (2009) found that the impact of pain intensity on physical quality of life was mediated by pain beliefs and behaviours (i.e. pain willingness subscale of the Chronic Pain Acceptance Questionnaire), demonstrating that presence of chronic pain alone is not a predictor of impact on physical function ${ }^{[1]}$. Forsyth et al. (2015) found that $89 \%$ of participants with haemophilia in an international sample reported that pain interfered to some extent with their activities in the previous month, with $26 \%$ reporting higher levels of interference and $21 \%$ reporting persistent pain ${ }^{[3]}$.

Previous research has demonstrated that people with chronic pain prioritise care that accounts for their personal situation and capacity to follow recommendations and is oriented towards achievement of their personal goals ${ }^{[33]}$. Street et al. propose that communication between patients and providers indirectly affects health outcomes such as pain intensity and interference by influencing patients' self-efficacy to manage their condition ${ }^{[16]}$. In a study primarily involving male veterans with chronic pain, Ruben et al. (2018) found that more positive perceptions of patient-provider communication were associated with lower pain intensity and pain interference scores and higher levels of self-efficacy to manage their health ${ }^{[20]}$. Although directionality of these relationships cannot be determined from that study, positive communication, with instruction on selfmanagement skills, reassurance, and encouragement, could be expected to influence self-efficacy to selfmanage and thereby have a positive impact on pain management. Simply stated, communication about pain management can have a therapeutic effect.

The PTPQ is intended to be used as a guide to facilitate discussions about pain management options as a means of promoting self-efficacy in selfmanagement skills. As such, it was structured to collect a focused pain history including multidimensional elements recommended in pain assessment clinical practice guidelines ${ }^{[34-36]}$. Each of the treatment team members may address different sections of the questionnaire with the patient, thereby streamlining the interactions about pain and reducing the need for patients to repeat their description of the pain experience and treatments used. The PTPQ includes a checklist of common pain treatments which clinicians can use to determine whether the patient is using a broad range of recommended treatments, including both pharmacologic and nonpharmacologic strategies. If treatment benefits are achieved as a result of the use of the PTPQ, this could be attributable to the discussion of treatment options, self-assessment of capacity to use the treatment, and problem solving through challenges identified. The treatment checklist could be used to guide members of the multidisciplinary care team to provide education and supportive interventions to promote self-management. The PTPQ could also be used to open discussions about the patient's capacity to follow treatment recommendations and determine if the patient requires additional care, resources, education or training to manage pain. The need for referrals to community-based providers, such as mental healthcare providers or physician specialists (e.g. pain specialists or multidisciplinary pain clinics), and support for resource access could also be identified and referrals expedited.

A qualitative approach was used to ensure that the PTPQ was developed in a manner that would maximise content validity. This approach has been 
recognised in the literature as an acceptable and patient-oriented process for tool development ${ }^{[37]}$. Brod et al. (2009) define content validity as "the measurement property that assesses whether items are comprehensive and adequately reflect the patient perspective for the population of interest. In addition, content validity provides evidence that formatting, instructions and response options are relevant, and the measure is understandable and acceptable to patients." Given that components of a focused pain history are well established and have been described in clinical practice guidelines, the research team did not feel that a rigorous grounded theory approach was necessary for item development. Cognitive interviews were conducted with patient participants until no further substantive changes were identified. The PTPQ was then approved by the multidisciplinary working group and consultant psychologist and pharmacist. Over 95\% of the clinical sample surveyed had no suggested revisions and reported that the PTPQ contained all relevant items for clinical communication about pain. It should be noted, however, that content validity cannot truly be said to occur until the measure shows responsiveness to change with a successful intervention. Further research will be required to examine this.

The PTPQ demonstrates reasonable clinical feasibility with a relatively low median completion time and high item response rate. Two participants who did not report pain found the questions on the PTPQ to be confusing. When providing the questionnaire for completion in the clinic setting, clinicians could prevent this confusion by informing patients on how to respond to the questions if they have no pain (e.g. leave the body diagram blank, circle 0 on the pain intensity questions). The working group decided to not implement changes recommended to the PTPQ by participants regarding an increase in the amount of response space to allow patients to explain their responses in more depth. Since the open text questions were left blank by half of participants, and since the PTPQ is intended to facilitate clinical discussion, the group decided that these recommendations would increase the number of pages or time required to complete the questionnaire and likely not enhance the value of the questionnaire for most patients and clinicians.

\section{Strengths and limitations of the research}

The PTPQ is unique from other general multidimensional pain assessment tools, such as the McGill Pain Questionnaire ${ }^{[38]}$ and Brief Pain Inventory [39], in that it is condition-specific and contains a multimodal treatment checklist. Strengths of the PTPQ include development through a codesign approach using broad engagement of both patients and clinicians in item selection and refinement through working group meetings, cognitive interviews, and clinical feasibility testing which followed an established tool development framework. A limitation of this research is that tool development and feasibility testing were conducted in one clinic with a small number of patient participants. It should be noted, however, that this clinic serves the entire bleeding disorder population of the Saskatchewan province, and the clinicians involved are leaders and active members of discipline-specific working groups of the Canadian Hemophilia Society (e.g. Canadian Physiotherapists in Hemophilia Care). The PTPQ is in the early stages of development and should be subject to further research to determine if it is valid and reliable and achieves its intended objectives of supporting clinical communication about pain.

\section{Future directions}

Further research is needed to determine if the PTPQ is clinically acceptable outside of the clinic and province in which it was developed. This research should also examine clinician perspectives on the clinical utility of the PTPQ, and whether use of the PTPQ impacts clinical decision-making. An Implementation Science approach ${ }^{[40]}$ to exploring the contextualisation of the PTPQ and the organisational characteristics that predict how the PTPQ is applied in different clinics will inform recommendations for application. Future research will need to determine if the PTPQ impacts clinical communication between patients and healthcare providers and between multidisciplinary healthcare team members, and whether communication is a mediating factor that influences pain outcomes. In turn, this would inform future research to support aspects of communication that most effectively optimise pain outcomes.

The composite pain score on the PTPQ was associated in the expected direction with disability status measured with the CPGS. Although the PTPQ is not intended as a diagnostic tool for measurement of a specific construct, further psychometric testing of the PTPQ is warranted to determine its reliability and validity. Clinical teams should be aware of potential limitations of implementing the PTPQ given it is in early stages of psychometric testing 


\section{CONCLUSIONS}

Recent calls to action have recommended development of standardised approaches to management of pain in patients with haemophilia ${ }^{[6,8]}$. This would necessarily include improving the capacity of clinicians in bleeding disorder treatment clinics to assess, educate, and communicate with patients about pain. The PTPQ is a clinically feasible PRO measure that shows promise for assessing the multidimensional nature of pain in adults with bleeding disorders in outpatient settings and facilitating communication between patients and clinicians about condition-specific pain treatment options. Further research is needed to evaluate the clinical utility and reliability of the PTPQ as well as to determine if communication about pain with the PTPQ affects pain outcomes in patients.

\section{ACKNOWLEDGEMENTS}

The authors would like to acknowledge the contributions of Michelle Sims (social worker) and O'Lynda Lovas (nurse) for initial working group participation, and Dr Bryan Acton (psychologist) and Richard Schlichemeyer (pharmacist) for providing feedback on the PTPQ.

The authors have advised no interests that might be perceived as posing a conflict or bias.

Informed consent was obtained from the participants in the evaluation study reported in this paper.

\section{ORCID}

Susan M Tupper (iD) https://orcid.org/0000-0003-3736-357X Pamela Downe (iD https://orcid.org/0000-0002-5557-6758

\section{REFERENCES}

1. Elander J, Robinson G, Mitchell K, Morris J. An assessment of the relative influence of pain coping, negative thoughts about pain, and pain acceptance on health-related quality of life among people with haemophilia. Pain 2009; 145: 169-75. doi: 10.1016/j.pain.2009.06.004.

2. Van Galen KPM, Sanders YB, Vojinovic U, et al. Joint bleeds in von Willebrand disease patients have significant impact on quality of life and joint integrity: a cross-sectional study. Haemophilia 2015; 21: e185-e192. doi: 10.1111/ hae.12670.

3. Forsyth AL, Witkop M, Lambing A, et al. Associations of quality of life, pain, and self-reported arthritis with age, employment, bleed rate, and utilization of haemophilia treatment center and health care provider services: results in adults with haemophilia in the HERO study. Patient Prefer Adherence 2015; 9: 1549-60. doi: 10.2147/PPA.S87659

4. Witkop M, Lambing A, Divine G, et al. A national study of pain in the bleeding disorders community: a description of haemophilia pain. Haemophilia 2012; 18: e115-e119. doi: 10.1111/j.1365-2516.2011.02709.x.
5. Holstein K, Klamroth R, Richards M, et al. Pain management in patients with haemophilia: a European survey. Haemophilia 2012; 18: 743-52. doi: 10.1111/j.1365-2516.2012.02808.x.

6. Riley RR, Witkop M, Hellman E, Akins S. Assessment and management of pain in haemophilia patients. Haemophilia 2011; 17: 839-45. doi: 10.1111/j.1365-2516.2011.02567.x.

7. Humphries TJ, Kessler CM. The challenge of pain evaluation in haemophilia: can pain evaluation and quantification be improved by using pain instruments from other clinical situations? Haemophilia 2013; 19: 181-7. doi: 10.1111/hae.12023.

8. Young G, Tachdjian R, Baumann K, Panopoulos G. Comprehensive management of chronic pain in haemophilia. Haemophilia 2014; 20: e113-e120. doi: 10.1111/hae.12349.

9. Witkop M, Lambing A, Kachalsky E, et al. Assessment of acute and persistent pain management in patients with haemophilia. Haemophilia 2011; 17 (4): 612-19. doi: 10.1111/j.13652516.2010.02479.x.

10. de Moerloose P, Fischer K, Lambert T, et al. Recommendations for assessment, monitoring, and follow-up of patients with haemophilia. Haemophilia 2012; 18 (3): 319-25. doi: 10.1111/j.1365-2516.2011.02671.x.

11. Williams AC, Craig KD. Updating the definition of pain. Pain 2016; 157 (1): 2420-23. doi: 10.1097/j. pain.0000000000000613.

12. Fillingim RB, Loesser JD, Barion R, Edwards RR. Assessment of chronic pain: domains, methods, and mechanisms. J Pain 2016; 17 (9 Suppl): T10-20. doi: 10.1016/j.jpain.2015.08.010.

13. Turk DC, Fillingim RB, Ohrbach R, Patel KV. Assessment of psychosocial and functional impact of chronic pain. J Pain 2016; 17 (9 Suppl): T21-49. doi: 10.1016/j.jpain.2016.02.006

14. Auerswald G, Dolan G, Duffy A, et al. Pain and pain management in haemophilia. Blood Coagul Fibrinolysis 2016; 27 (8): 845-54. doi: 10.1097/MBC.0000000000000571.

15. Lambing A, Witkop M, Humphries TJ. Complementary and alternative therapy (CAM) in haemophilia pain management: a review of published literature. J Haem Pract 2019; 6 (1): 7-18. doi: $10.17225 /$ jhp00122.

16. Street RL. How clinician-patient communication contributes to health improvement: modeling pathways from talk to outcome. Patient Educ Couns 2013; 92: 286-91. doi: 10.1016/j.pec.2013.05.004.

17. Feldman-Stewart $D$, Brundage MD. A conceptual framework for patient-provider communication: a tool in the PRO research tool box. Qual Life Res 2009; 18 (1): 109-14. doi: 10.1007/s11136-008-9417-3.

18. Dorflinger L, Kerns RD, Auerbach SM. Providers' roles in enhancing patients' adherence to pain self-management. Transl Behav Med 2013; 3 (1): 39-46. doi: 10.1007/s13142-012-0158-z.

19. Zanetti CA, Taylor N. Value in co-creation in healthcare through positive deviance. Healthc (Amst) 2016; 4: 277-81. doi: 10.1016/j.hjdsi.2016.06.003.

20. Ruben MA, Meterko M, Bokhour BG. Do patient perceptions of provider communication relate to experiences of physical pain? Patient Educ Couns 2018; 101 (2): 209-13. doi: 10.1016/j.pec.2017.08.002.

21. Heckman BW, Mathew AR, Carpenter MJ. Treatment burden and treatment fatigue as barriers to health. Curr Opin Psychol 2015; 1 (5): 31-36. doi: 10.1016/j.copsyc.2015.03.004.

22. Valderas JM, Ferrer M, Mendivil J, et al; Scientific Committee on "Patient-Reported Outcomes" of the IRYSS Network. 
Development of EMPRO: a tool for the standardized assessment of patient-reported outcome measures. Value Health 2008; 11 (4): 700-8. doi: 10.1111/j.15244733.2007.00309.x.

23. Izumi S, Vandermause R, Benavides-Vaello S. Adapting cognitive interviewing for nursing research. Res Nurs Health 2013; 36 (6): 623-33. doi: 10.1002/nur.21567.

24. Knafl K, Deatrick J, Gallo A, et al. The analysis and interpretation of cognitive interviews for instrument development. Res Nurs Health 2007; 30 (2): 224-34. doi: 10.1002/nur.20195.

25. Drennan J. Cognitive interviewing: verbal data in the design and pretesting of questionnaires. J Adv Nurs 2003; 42 (1): 57-63.

26. Smith BH, Penny Kl, Purves AM, et al. The Chronic Pain Grade questionnaire: validation and reliability in postal research. Pain 1997; 71: 141-7.

27. Von Korff M, Ormel J, Keefe FJ, Dworkin SF. Grading the severity of chronic pain. Pain 1992; 50: 133-49.

28. Hawker GA, Mian S, Kendzerska T, French M. Measures of adult pain: Visual Analog Scale for Pain (VAS Pain), Numeric Rating Scale for Pain (NRS Pain), McGill Pain Questionnaire (MPQ), Short-Form McGill Pain Questionnaire (SF-MPQ), Chronic Pain Grade Scale (CPGS), Short Form-36 Bodily Pain Scale (SF-36 BPS), and Measure of Intermittent and Constant Osteoarthritis Pain (ICOAP). Arthritis Care Res (Hoboken) 2011; 63 (Suppl 11): S240-52. doi: 10.1002/acr.20543.

29. Salaffi FF, Stancati AF, Grassi W. Reliability and validity of the Italian version of the Chronic Pain Grade questionnaire in patients with musculoskeletal disorders. Clin Rheumatol 2006;25: 619-31. doi: 10.1007/s10067-005-0140-y.

30. Witkop M, Neff A, Buckner TW, et al. Self-reported prevalence, description and management of pain in adults with haemophilia: methods, demographics and results from the Pain, Functional Impairment, and Quality of life (P-FiQ) study. Haemophilia 2017; 23: 556-65. doi: 10.1111/ hae.13214.

31. Wallny $T$, Hess $L$, Seuser $A$, et al. Pain status of patients with severe haemophilic arthropathy. Haemophilia 2001; 7 (5): 453-58. doi: 10.1046/j.1365-2516.2001.00540.x.

32. Häuser W, Schmutzer G, Hilbert A, Brähler E, Henningsen P. Prevalence of chronic disabling noncancer pain and associated demographic and medical variables: a cross- sectional survey in the general German population. Clin J Pain 2015;31: 886-92. doi: 10.1097/AJP.0000000000000173.

33. Burton CD, Entwistle VA, Elliott AM, et al. The value of different aspects of person-centred care: a series of discrete choice experiments in people with long-term conditions. BMJ Open 2017; 7(4): e015689. doi: 10.1136/bmjopen-2016-015689.

34. Registered Nurses' Association of Ontario. Assessment and Management of Pain. Clinical Best Practice Guidelines. Third edition. ON: Registered Nurses' Association of Ontario; 2013. Available from https://rnao.ca/sites/rnao-ca/files/ AssessAndManagementOfPain2014.pdf (accessed 11 March 2020)

35. Scottish Intercollegiate Guidelines Network (SIGN). Management of Chronic Pain: A National Clinical Guideline. SIGN 136. Revised edition, August 2019. Available from: https://www.sign.ac.uk/sign-136-management-of-chronicpain (accessed 11 March 2020).

36. Hooten M, Thorson D, Bianco J, et al; Institute for Clinical Systems Improvement. Pain: Assessment, Non-Opioid Treatment Approaches and Opioid Management. Updated August 2017. Available from: http://www.icsi.org/wp-content/ uploads/2019/01/Pain.pdf (accessed 11 March 2020).

37. Brod M, Tesler LE, Christensen TL. Qualitative research and content validity: developing best practices based on science and experience. Qual Life Res 2009; 18(9): 1263-78. doi: 10.1007/s11136-009-9540-9.

38. Melzack R. The McGill Pain Questionnaire: major properties and scoring methods. Pain 1975; 1(3): 227-99.

39. Cleeland CS. Pain assessment in cancer. In: Osoba D, ed. Effect of Cancer on Quality of Life. Boca Raton, FL: CRC Press, Inc.; 1991: 293-305.

40. Edwards N. Barker PM. The importance of context in implementation research. J Acquir Immune Defic Syndr 2014; 67 (Suppl 2): S157-62. doi: 10.1097/QAl.0000000000000322.

HOW TO CITE THIS ARTICLE:

Tupper SM, Nilson JA, King J, Downe P, Hodgson N,

Schlosser T, Brose K. Development and clinical feasibility

testing of the Pain Treatment Planning Questionnaire.

J Haem Pract 2020; 7(1): 12-[12-24]. https://doi.

org/10.17225/jhp00155 


\section{APPENDIX A}

\section{Cognitive interview guide questions}

Instructions read to participant at the beginning of the interview:

Please think out loud as you answer each question, in other words, say aloud everything that you are thinking as you read and answer the question. There are no right or wrong ways to think about the questions. We simply want to know what the question makes you think and how you decide to select the answer that you give. As you give an answer we will ask some follow-up questions to try to better understand your thoughts about the question. We will also be asking you to explain what you mean by your answers. Your answer will help us improve the questionnaire to make it more understandable and easier for people to answer.

Sample Verbal Probing Questions: (probes based on participant responses and behaviors during the interview)

1. What does this question mean to you in your own words?

2. How would you reword that question to make it easier to understand?

3. Would you reorganize the arrangement of questions and answer options on the page in any way to make more sense or make it easier to follow?

4. What do you think of when you read (word in question)?

5. How did you choose your answer?

6. What does your answer mean to you in your own words?

7. Does your answer convey everything about this topic that you would want to share with the bleeding disorders team?

8. Is there anything not included in this questionnaire that you would want the bleeding disorders team to know about your pain? 
Pain Treatment Planning Questionnaire We want to better understand your pain, both pain related to your bleeding disorder or other pain. We will use your answers to help plan treatment that will reduce pain and help you do the things you want to do. Please answer questions on both sides of the page.

Date:

1. Indicate on the diagram below where you felt bodily pain from any cause in the past $\mathbf{3 0}$ days.

Circle any areas where you have had pain or discomfort. Mark with X's any areas where you have had numbness, tingling or pins and needles sensations.
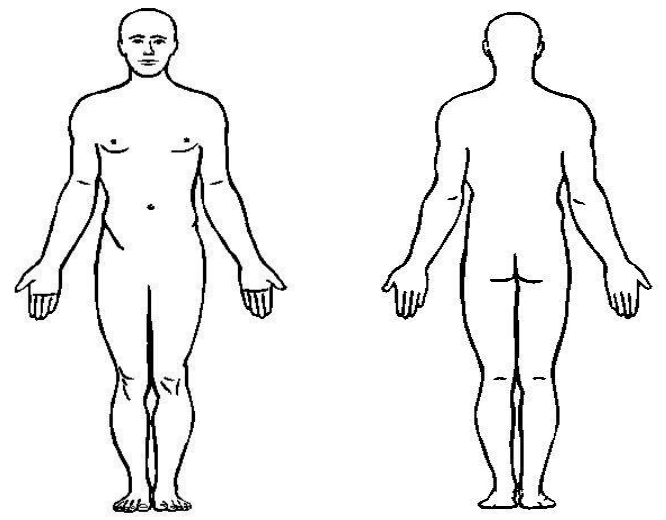

2. Please answer the following questions about how strong or intense your pain has been the past 30 days. When answering, think about the area that is your main concern. (Circle the number)

a) How would you rate your pain right now?

$\begin{array}{ccccccccccc}0 & 1 & 2 & 3 & 4 & 5 & 6 & 7 & 8 & 9 & \begin{array}{c}10 \\ \text { Most pain } \\ \text { poin }\end{array}\end{array}$

b) How would you rate the lowest level of pain you have had this past 30 days?

$\begin{array}{ccccccccccc}\begin{array}{c}\text { No } \\ \text { pain }\end{array} & 1 & 2 & 3 & 4 & 5 & 6 & 7 & 8 & 9 & \begin{array}{c}10 \\ \text { Most pain } \\ \text { possible }\end{array} \\ \end{array}$

c) How would you rate the most/worst pain you have had this past 30 days?

$\begin{array}{ccccccccccc}\underset{N}{0} & 1 & 2 & 3 & 4 & 5 & 6 & 7 & 8 & 9 & \begin{array}{c}10 \\ \text { pain }\end{array} \\ \text { post pain } \\ \text { possible }\end{array}$

d) How would you rate your usual level of pain on a typical day this past 30 days?

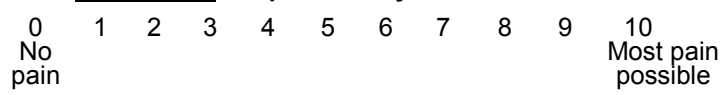

e) How often do you usually have pain? (Circle word)

$\begin{array}{cccc}\begin{array}{c}\text { Never or } \\ \text { rarely }\end{array} \text { a mont once } & \begin{array}{c}\text { About once } \\ \text { a week few times }\end{array} & \begin{array}{c}\text { Daily } \\ \text { a week }\end{array} & \end{array}$

Please complete questions on other side.
3. The following words are sometimes used to describe how pain feels. Circle $A L L$ the words that describe the pain you felt in the past 30 days (if applicable).

\begin{tabular}{|c|c|c|c|c|c|}
\hline Throbbing & Aching & Sharp & Tender & Pressure & Tiring \\
\hline Nagging & Burning & $\begin{array}{l}\text { Sensitive } \\
\text { to touch }\end{array}$ & $\begin{array}{c}\text { Electric } \\
\text { shocks }\end{array}$ & Tingling & Prickling \\
\hline Bursting & Miserable & Shooting & Constant & $\begin{array}{c}\text { Comes } \\
\text { and goes }\end{array}$ & \\
\hline
\end{tabular}

Please list any other words you use to describe your pain.

4. a) What made your pain less noticeable in the past $\mathbf{3 0}$ days (e.g. ice, activities, positions)?

b) What made your pain worse in the past 30 days (e.g. activities, positions)?

5. a) Is there a time of day that your pain is usually more noticeable (worse)? (Circle) Yes / No

b) If yes, what time of day is your pain worse?

6. a) In the past $\mathbf{3 0}$ days, did you limit any of your activities because of pain (e.g. work/school, socialize, sex)? Yes / No b) If yes, how often and what activities did you limit?

7. a) In the past $\mathbf{3 0}$ days, did pain affect your mood? Yes / No b) If yes, how often and what was the effect?

8. Overall, how satisfied are you with your current pain management?

\begin{tabular}{|c|c|c|c|c|}
\hline $\begin{array}{c}\text { Very } \\
\text { unsatisfied }\end{array}$ & $\begin{array}{c}\text { A little } \\
\text { unsatisfied }\end{array}$ & $\begin{array}{c}\text { Neither } \\
\text { satisfied } \\
\text { nor } \\
\text { unsatisfied }\end{array}$ & $\begin{array}{c}\text { A little } \\
\text { satisfied }\end{array}$ & $\begin{array}{c}\text { Very } \\
\text { satisfied }\end{array}$ \\
\hline
\end{tabular}

9. Treatment Goals: How can we help you?

(C) 2019, S.M. Tupper. All rights reserved. Contact susan.tupper@usask.ca for permissions 


\section{Pain Treatment Planning Questionnaire Page 2 of 2}

Patient Name: HSN:

What have you used to help with your pain since your last clinic visit. Your treatment team will use your answers to discuss pain management options with you.

INSTRUCTIONS: Mark the box with a $\checkmark$ beside any treatments you have used since your last bleeding disorders clinic visit.

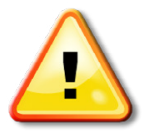

(NOTE: not all of these treatments are recommended. Talk to your health care provider about what is right for you)

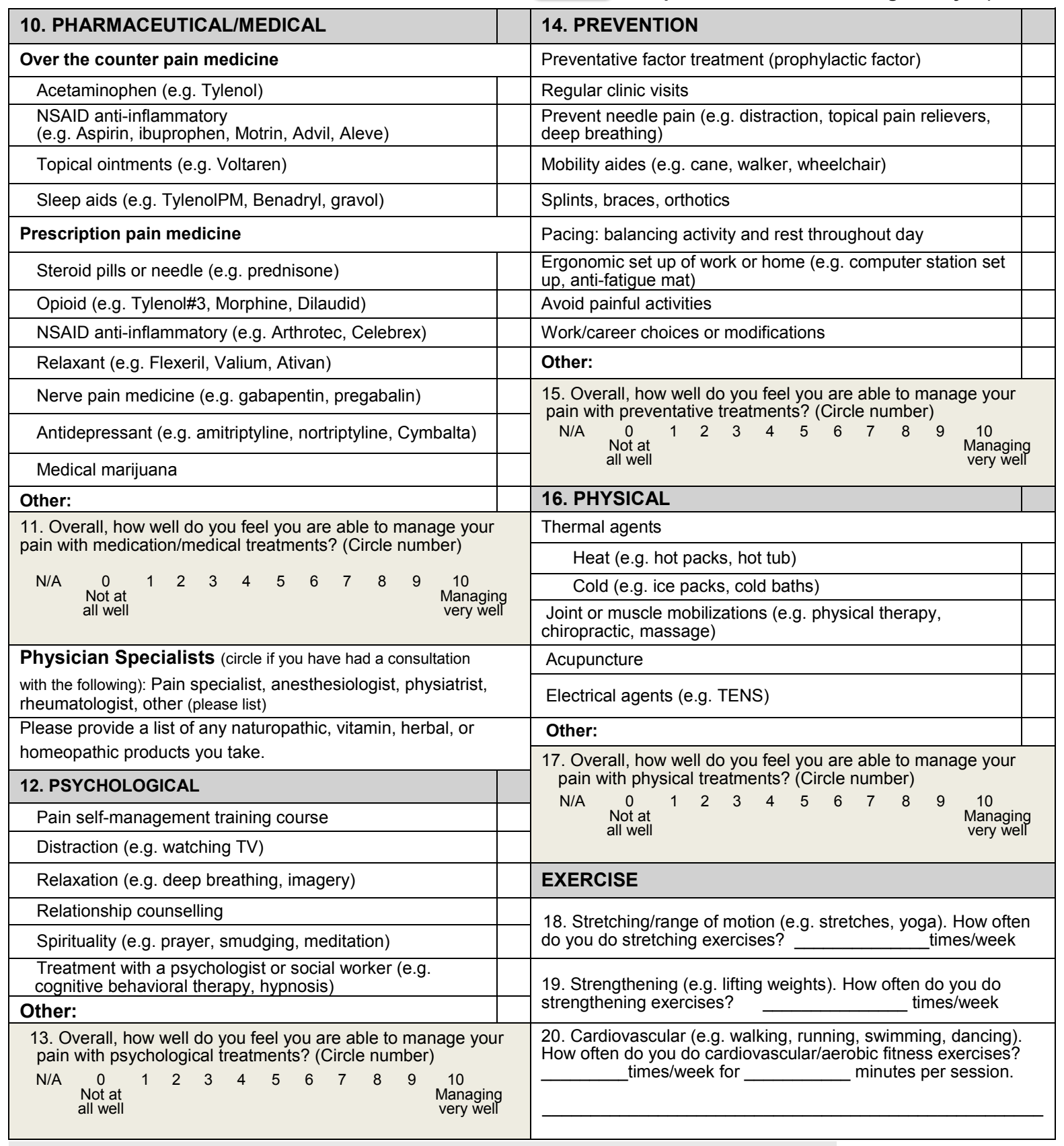

Initial when reviewed:

Hematologist $-\mathrm{RN}-\mathrm{PT}$

\section{PREVENTION}

Prevent needle pain (e.g. distraction, topical pain relievers, deep breathing)

Mility aides (e.g. cane, walker, wheelchair)

Splints, braces, orthotics up, anti-fatigue mat)

Other:

Overall, how well do you feel you are able to manage your ain with preventative treatments? (Circle number)

N/A 0

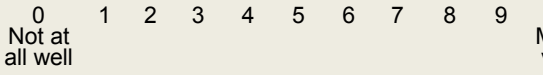
Managing

\section{PHYSICAL}

Joint or muscle mobilizations (e.g. physical therapy, chiropractic, massage)

Acupuncture

Electrical agents (e.g. TENS)

Overall, how well do you feel you are able to manage your pain with physical treatments? (Circle number)

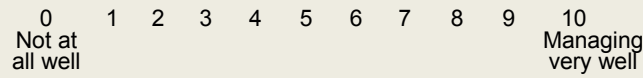

PT - SW - Other The End-Thank You. 